\title{
Success Through Community Cultural Wealth: Reflections From Black Female College Athletes at a Historically Black College/University (HBCU) and a Historically White Institution (HWI)
}

\author{
Joseph N. Cooper \\ University of Connecticut \\ Christa J. Porter \\ Kent State University \\ Tiffany J. Davis \\ University of Houston
}

\begin{abstract}
The purpose of this study was to explore the experiences of Black female college athletes at a Division I historically Black college/university (HBCU) and historically White institution (HWI) and identify key influences that facilitated their academic achievement and positive educational experiences. Two focus groups and eight individual interviews were conducted with three Black female college athletes at a HBCU and five Black female college athletes at a HWI. An 8-item demographic questionnaire was administered to obtain information related to the participants' personal backgrounds. Yosso's (2005) community cultural wealth framework was incorporated to highlight individual and environmental influences that contributed to participants' positive educational and developmental outcomes. Findings revealed participants accessed and leveraged various forms of familial, resistant, aspirational, social, and navigational capital to overcome challenges and excel in college. Implications for policy and practice are discussed.
\end{abstract}

Keywords: black female college athletes, community cultural wealth, critical race methodology, academic achievement, intercollegiate athletics

Cooper is with the Department of Educational Leadership, University of Connecticut, Storrs, Connecticut. Porter is with the College of Education, Health, and Human Services, Kent State University, Kent, Ohio. Davis is with the University of Houston, Educational Leadership and Policy Studies, Houston, Texas. Address author correspondence to Joseph Cooper at joseph.cooper@uconn.edu. 


\section{Introduction}

The organizational structures and informal practices at institutions of higher education are a microcosm of the broader United States (U.S.) whereby dominant ideologies of patriarchy and White supremacy are deeply embedded and perpetuated (Howard-Hamilton, 2003). Black female college students are often ascribed roles and expectations and forced to fit within discourses primarily centered on their Black male and/or White female peers (Howard-Hamilton, 2003). However, the intersectionality of their oppressed identities as Black females requires appropriate empirical examinations to more fully understand individual and collective identity development and socialization processes before and during their campus experiences (Porter \& Dean, 2015). More specifically, Black female college athletes ${ }^{1}$ is one subgroup that has historically been and continues to be significantly disadvantaged by cultural incongruences between their self-identities/backgrounds and the campus environments at many U.S. postsecondary institutions (Carter-Franicique, Dortch, \& Carter-Phiri, 2017; Corbett \& Johnson, 2000). The marginalization of this subgroup is unique due to the subordination of their intersecting identities including their $\mathrm{sex}^{2}$, race, and athletic status (Bruening, 2005; Bruening, Armstrong, \& Pastore, 2005; Carter, 2008; Corbett \& Johnson, 2000; Person, Benson-Quaziena, \& Rogers, 2001; Withycombe, 2011). For example, despite graduating at higher rates compared with their Black male college athlete peers, an abundance of research related to race, sport, and education has reinforced patriarchal norms whereby the latter group has been the central focus whereas the former group has been marginalized to the periphery (Bruening, 2005; Tryce \& Brooks, 2010).

Notwithstanding, Black female college athletes have concurrently experienced social isolation, negative psychological outcomes, and perpetual encounters with discriminatory treatment (race and sex related) particularly at historically White institutions ${ }^{3}$ (HWIs), which constitute a majority of the National Collegiate Athletic Association (NCAA) membership and sites where extant research on this subgroup has been conducted (Bruening et al., 2005; Bernhard, 2014; Carter, 2008; Harmon, 2009; Withycombe, 2011). In addition to HWIs, there is also a need to examine the experiences of Black female college athletes across different institutional types including at historically Black colleges and universities (HBCUs), which have been found to cultivate positive educational experiences and outcomes for Black students in general and Black college athletes in particular (Cooper, 2013; Cooper \& Cooper, 2015; Hawkins, Cooper, Carter-Francique, \& Cavil, 2015). In an effort to challenge racism and sexism in the sport education literature, which privileges Whiteness (HWIs emphasized over HBCUs) and maleness (male college athletes across White and Black racial groups compared to female college athletes), as well as to foster more equitable educational and developmental outcomes across subgroups and institutional types, the current study examined the experiences and perspectives of Black female college athletes ${ }^{4}$ at a Division I (D-I) HBCU and HWI.

A major reason for the invisibility or lack of attention to Black female college athletes is the fact that when analyzed they are often clustered with either their White female counterparts on the basis of sex or their Black male counterparts on the basis of race (Bruening, 2005). Consequently, these analyses do not take into 
account the unique experiences and intersecting identities of Black females who participate in athletics (Carter, 2008; Corbett \& Johnson, 2000; Withycombe, 2011). For example, recent data from a NCAA (2016) report revealed African American ${ }^{5}$ female student athletes $(84 \%)$ consistently graduate at rates lower than their White student athlete counterparts (male-87\% and female-95\%), yet higher than Black male student athletes (70\%). Despite enrolling with similar precollege characteristics as their Black male peers (Sellers, Kuperminc, \& Damas, 1997), Black female college athletes have identified ways to navigate the contested terrains at HWIs despite being underrepresented, marginalized, and often overlooked (Carter, 2008; Cooper, Cooper, \& Baker, 2016). Moreover, there is a need to move beyond focusing on Black female college athletes' encounters with racism and sexism and explore aspects of their lived experiences related to positive educational and developmental outcomes (Cooper, et al., 2016).

Given the unique experiences and positionality of Black female college athletes, it is necessary to engage in antideficit research that encompasses intersectional lenses (Collins, 1986, 1990, 2000; Crenshaw, 1991) to identify and create effective holistic supports for this subgroup (Carter-Francique, 2013; Carter-Francique, Cooper et al., 2016; Dortch, \& Carter-Phiri, 2017) and more broadly demonstrate a stronger commitment to equity in education and sport. Thus, our current study differs from and builds upon previous research in its centrality of an antideficit approach in the examination of Black female college athletes at two distinct institutional types. Understanding effective navigational strategies and specific conditions across institutional types will enable for a better understanding of key individual and institutional factors that enhance their developmental outcomes. Hence, the purpose of this study was to explore the experiences of Black female college athletes at a D-I HBCU and HWI and identify key influences that facilitated their academic achievement and positive educational experiences.

\section{Literature Review}

The extant literature on Black female college athletes has highlighted their unique and complex experiences in both academic and athletic contexts (Bernhard, 2014; Bruening et al., 2005; Carter, 2008; Carter, Dortch, \& Carter-Phiri, 2017; Carter \& Hart, 2010; Cooper et al., 2016; Foster, 2003; Harmon, 2009; Sellers et al., 1997; Withycombe, 2011). Consistent with the literature on African American female students in college (Howard-Hamilton, 2003), research on African American female college athletes argued their experiences are distinct from their same-race male and different-race female counterparts (Sellers et al., 1997). As such, within this literature review, the authors will highlight research related to Black female college athletes' experiences in college including campus climates at HWIs (Bernhard, 2014; Bruening et al., 2005; Carter, 2008; Carter-Francique, Dortch, \& CarterPhiri, 2017; Withycombe, 2011)and HBCUs (Carter-Francique \& Richardson, 2015; Charlton, 2011; Cooper \& Cooper, 2015) and the emerging body of work focused on their engagement in educationally purposeful activities (Comeaux \& Harrison, 2011; Comeaux, Speer, Taustine, \& Harrison, 2011; Gaston-Gayles \& $\mathrm{Hu}, 2009$; Umbach et al., 2006). This literature provides a necessary context for understanding the purpose and valued added of the current study. 


\section{Collegiate Experiences}

Despite the significant progress in female sports since the passage of Title IX of the Education Amendments of 1972, athletic spaces remain largely sexist environments whereby female athletes are subjugated by institutional systems rooted in patriarchy (Corbett \& Johnson, 2000; Flowers, 2015; Tryce \& Brooks, 2010). Previous research has highlighted how African American female college athletes experience multilevel marginalization at the macro/societal level (via mass media), meso/institutional level (underrepresentation of same race and gender role models in athletic leadership positions), and micro/interpersonal level (encounters with negative stereotypes) (Bruening et al., 2005; Carter, 2008; Withycombe, 2011). The pervasiveness of negative stereotypes against Black female college athletes at HWIs in conjunction with the underrepresentation of Blacks in the general student body has been identified as a primary contributor for their social isolation. For example, findings of social isolation were documented in Bernhard's (2014) study when African American female student athletes at a D-I HWI expressed their unmet needs such as a lack of campus organizations designed for Black females, limited access to Black churches within a reasonable distance to the campus, and a dearth of culturally relevant outlets for their personal care. More recently, Black female college athletes in Carter-Francique, Dortch, and Carter-Phiri's study (2017) described how their White peers exemplified levels of privilege and entitlement that reinforced broader societal inequities in terms of stratification of resources and access based on "race, social class, and familiarity with higher education" (p. 31).

Campus Climate at HWIs. Beyond single institution qualitative case studies, quantitative studies using large sample sizes have also illustrated the extent to which Black female college athletes experience negative campus racial climates at HWIs. Using a national student athlete dataset with representation across all three NCAA Divisions (I, II, and III), Rankin et al. (2011) analyzed campus climate perceptions and found women and student athletes of color more likely to experience harassment compared with their peers who were male and White. This harassment involved being excluded from specific activities to more overt discrimination in the form of derogatory comments. In another study using national data, Hoffman, Rankin, and Loya (2016) found that women of color student athletes reported heightened negative perceptions of campus climate and experienced lower levels of academic success compared with White female student athletes. In summary, the campus racial climate at HWIs has a disparate impact on Black female college athletes due to their identities both within and beyond campus (Bruening, 2005; Carter, 2008; Person et al., 2001; Withycombe, 2011).

Campus Climate at HBCUs. In contrast, the campus climate at HBCUs has reflected nurturing and supportive spaces whereby Black students including Black female college athletes experience positive educational, sport, and developmental opportunities that were either nonexistent or significantly limited at HWIs (CarterFrancique \& Richardson, 2015; Charlton, 2011; Cooper, 2013; Cooper \& Cooper, 2015). Since their inception in the mid-1800s, HBCUs were founded with the primary mission of providing quality learning opportunities for Black students in a racist society that belittled their holistic self-worth (Fleming, 1984). In particular, from their initial years as teaching and vocational based institutions to the $21 \mathrm{st}$ 
century as purveyors of knowledge in a range of disciplines, skill acquisition, and cultural empowerment, Black women have experienced high levels of academic achievement and educational attainment at HBCUs (Allen et al., 2007; Fleming, 1984). In addition, Black female college athletes at HBCUs have consistently produced higher graduation rates compared with their Black male peers, which reflects their intellectual prowess and the positive relationship between academics and athletics at these institutions (NCAA, 2017). Moreover, dating back to the mid-1900s, HBCUs also served as progressive spaces for gender equity in terms of sporting opportunities (Carter-Francique \& Richardson, 2015). As a result of these expansive opportunities, HBCUs produced legendary Black female athletes such as Alice Coachman (Tuskegee University), Althea Gibson (Florida Agricultural and Mechanical University), and Wilma Rudolph (Tennessee State University) to name a few who not only excelled athletically on the international stage, but also remained socially engaged in the broader Black community and created pathways for their African American female athlete successors (CarterFrancique \& Richardson, 2015). In addition to producing athletic talent, HBCU coaches similar to their faculty and staff colleagues create a familial culture unique to these institutions whereby collective success was and remains prioritized and connected to broader communal goals of racial uplift and cultural empowerment (Carter-Francique \& Richardson, 2015; Cooper, 2013; Cooper, Cavil, \& Cheeks, 2014; Cooper \& Cooper, 2015; Hawkins et al., 2015). Related to the sociocultural influences, the preponderance of culturally empowering artifacts, curricula, and campus organizations and events (i.e., annual homecomings) also create a positive identity affirming environments for Black students including Black college athletes (Allen et al., 2007; Cooper, 2013; Cooper \& Cooper, 2015).

Benefits of Purposeful Engagement. Across institutional types, researchers have explored the influence of engagement in educationally purposeful activities on college athletes' social, psychological, and academic outcomes (Comeaux \& Harrison, 2011; Comeaux, Speer, Taustine, \& Harrison, 2011; Gaston-Gayles \& Hu, 2009; Umbach et al., 2006). For example, Gaston-Gayles and Hu (2009) found interacting with faculty, interaction with students other than teammates, and participation in academic related activities contributed to increased learning and communication skills for D-I student athletes regardless of background characteristics such as race, gender, and academic major. More germane to the current study, the authors also found that female and Black student athletes expressed higher levels of personal self-concept, which correlated with increased interaction with students other than teammates (Gaston-Gayles \& Hu, 2009). Similarly, Umbach et al. (2006) found that female student athletes across all three NCAA Divisions (I, II, and III) were more likely than their female student nonathletes to interact with faculty, participate in active and collaborative learning activities, and report higher levels of satisfaction with their overall college experience. Related to peer student athlete engagement, Comeaux, Speer, Taustine, and Harrison (2011) found Black student athletes' general academic self-concept was associated with developing close relationships with fellow student athletes who value education and enhancing their academic talents. Researchers have also documented numerous benefits for Black college athletes who participate in culturally relevant and responsive programming at both HWIs (Bimper, 2015, 
2016; Carter-Francique, 2013; Carter-Francique, Dortch, \& Carter-Phiri, 2017; Cooper, 2016) and HBCUs (Cooper, 2013).

Related to culturally relevant and responsive supports, several researchers have incorporated critical race theory (CRT), community cultural wealth (CCW; discussed in greater detail in the subsequent section), and social capital theories to explore how Black college athletes overcome challenges at HWIs (Bimper, 2015, 2016; Carter \& Hart, 2010; Carter-Francique, Hart, \& Cheeks, 2015; Carter-Francique, Hart, \& Steward, 2013). For example, Carter-Francique, Hart, and Cheeks (2015) used the social capital aspect of CCW to highlight how Black college athletes at a HWI relied on their parents and extended family members to provide support they were lacking at their institution (e.g., appraisal, emotional, and instrumental). Bimper (2016) applied social capital theory and CRT to examine various benefits associated with being involved in culturally relevant programs designed to enhance Black college athletes' network within and across cultural groups. Common themes across studies utilizing CRT and CCW involved: a) the recognition of racism and related forms of oppression in society and educational spaces, b) the implementation of culturally relevant and responsive supports, c) the presence of and access to caring mentors, and d) the validation and affirmation of cultural identities, knowledge, and resources as a form of resistance against oppressive norms. Building on the aforementioned literature, the current study incorporated CCW framework in the examination of key influences that contributed to the academic achievement and positive educational experiences of Black female college athletes at a D-I HBCU and HWI (Yosso, 2005).

\section{Theoretical Framework}

Originating from the foundations of CRT (Bell, 1992; Crenshaw, Gotanda, Peller, \& Thomas, 1995; Delgado \& Stefanic, 2001; Ladson-Billings \& Tate, 1995), CCW highlights resources Black, Latinx, Native American (also referred to as Indigenous People), and Asian people in the U.S. embody and activate to navigate a culture that is designed to marginalize and oppress their racial and cultural backgrounds (Yosso, 2005). Similar to CRT, CCW posits race and racism are deeply interwoven in the fabric of U.S. society and consequently Black, Latinx, Native American, and Asian people have been forced to adopt a set of skills and strategies to not only sustain their survival, but also to contribute to their enhanced quality of life (i.e., social mobility). In addition, this framework incorporates a range of concepts from academic fields such as sociology, economics, ethnic and cultural studies, history, women's studies, and law (Crenshaw et al., 1995; Yosso, 2005). In contrast to dominant narratives of that label Black people's (particularly African Americans') behaviors as anti-intellectual, unproductive, and apathetic (see Collins (2000) for an extensive analysis on this topic), Yosso (2005) asserted that reframing these distorted perspectives requires a reconceptualization of how traits and resources are viewed, acquired, and applied in different cultural contexts.

According to Yosso (2005), CCW "is an array of knowledge, skills, abilities, and contacts possessed and utilized by Communities of Color to survive and resist macro and micro-forms of oppression" (p. 77). The framework is comprised of six unique forms of capital: a) aspirational, b) navigational, c) social, d) linguistic, e) familial, and f) resistant. Aspirational capital refers to an individual's ability to 
persist toward their personal goals with limited resources while existing within a social system that largely disadvantages them. Navigational capital refers to the skills and knowledge associated with individual's ability to matriculate and excel within specific social institutions (i.e., educational system). Social capital refers to the presence and use of human relationships to enhance upward mobility. Linguistic capital refers to the language and communication skills that students bring with them to the college environment. Familial capital refers to cultural knowledge, history, and values that are transmitted among family members. Last, but not least, resistant capital refers to knowledge, skills, and behaviors that reflect a direct challenge to dominant ideologies and structures that subjugate Blacks, women, and various groups subjected to intersecting oppressions. Within the current study, five of the six CCW capital concepts were incorporated: familial, resistant, social, navigational, and aspirational. The following research questions guided the current study:

1. What personal influences contributed to Black female college athletes' academic achievement and positive educational experiences at a Division I HBCU and HWI?

2. What institutional influences contributed to Black female college athletes' academic achievement and positive educational experiences at a Division I HBCU and HWI?

\section{Methods}

\section{Site Selection and Participants}

Purposeful sampling was used to identify participants at two D-I institutions (Patton, 2002). An HBCU and a HWI were selected to explore intersecting themes across institutional contexts and to fill a gap in the literature in terms of using qualitative methods to explore the phenomenon of achievement among this subgroup. Both schools were ranked among the top 30 in their respective academic classifications in the U.S. News \& World Report rankings (U.S. News \& World Report, 2017). In terms of sociopolitical features, both institutions were classified as public, nonreligious based, and liberal arts schools. The eight participants in this study included three at D-I HBCU and five at a D-I HWI (see Table 1). Along with purposeful sampling, criterion-based selection was also incorporated to identify participants who could provide the most information-rich responses related to the phenomenon of interest (Patton, 2002). Participants were selected based on the following criteria: a) self-identified as a Black female, b) an active member of a varsity athletic team at a D-I HBCU or HWI, c) enrolled as a full-time student at a D-I HBCU or HWI, d) earned a 2.8 cumulative grade point average (GPA) or higher, and e) recognized by the Student Athlete Support Services (SASS) at their respective institutions as a high academic performing student.

Participants' academic classifications included first-year $(n=3)$, sophomore $(n=2)$, and junior $(n=3)$. Academic majors represented were Business Marketing $(n=2)$, Liberal Studies Management $(n=1)$, Accounting $(n=1)$, English $(n=1)$, Biology $(n=1)$, Undecided (later Human Development and Family Studies) $(n=$ $1)$, and Sport Promotions $(n=1)$. College GPA ranges included 2.80-2.99 $(n=2)$, 3.00-3.49 $(n=4)$, and 3.50-4.00 $(n=2)$. Career goals for the participants included 


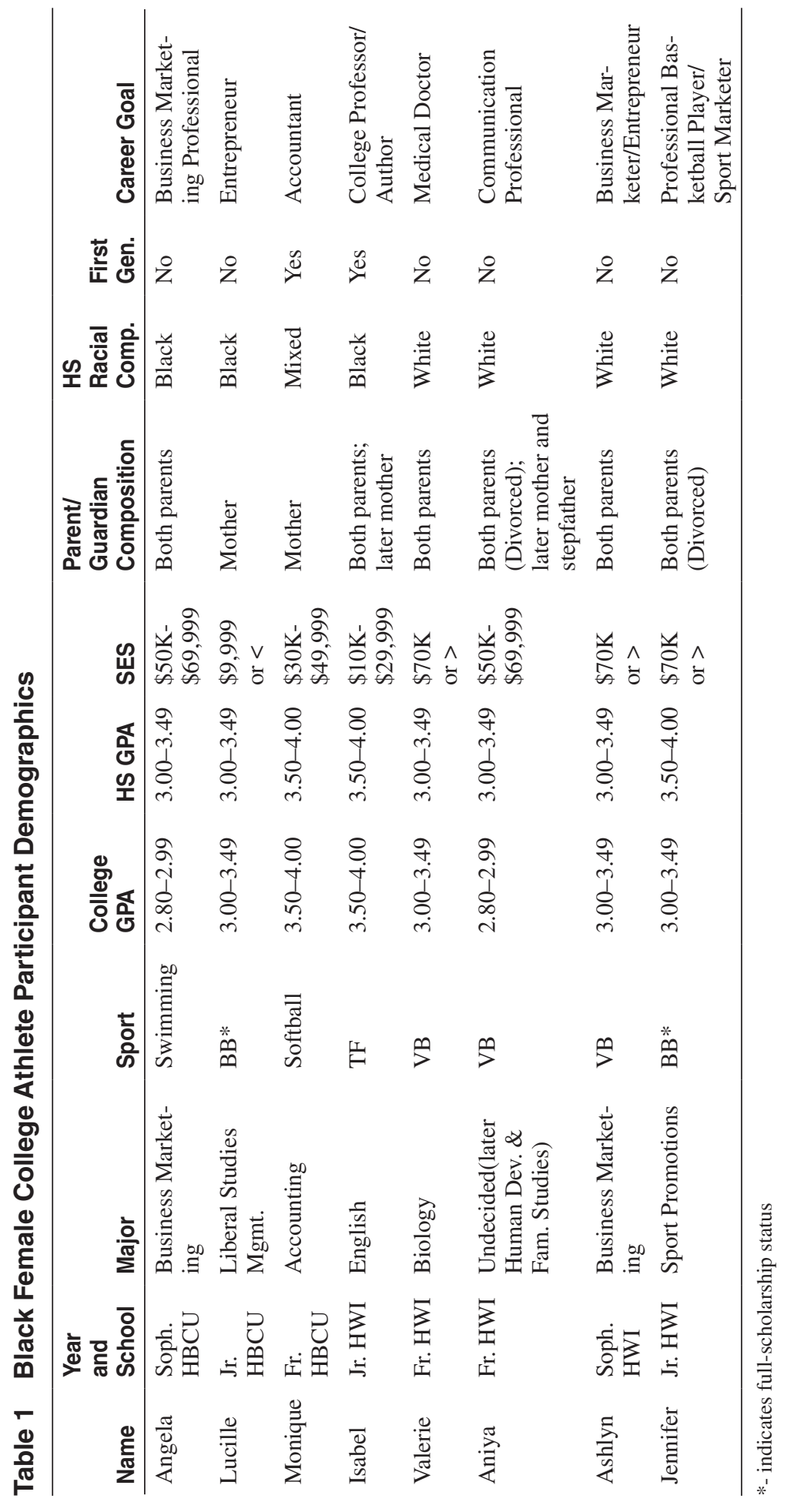


Business Marketing Professional $(n=1)$, Entrepreneur $(n=2)$, Accountant $(n=$ $1)$, College Professor and Author $(n=1)$, Medical Doctor $(n=1)$, Communication Professional $(n=1)$, and Professional Basketball Player and Sport Marketer $(n=1)$. Sport team affiliations included swimming $(n=1)$, basketball $(n=2)$, softball $(n=$ $1)$, track and field $(n=1)$, and volleyball $(n=3)$. The two basketball players were on full-scholarship while the remaining six participants from swimming, softball, track and field, and volleyball were on partial scholarships. Family socioeconomic statuses included working class $(\$ 49,999$ or below) $(n=3)$, middle-class $(\$ 50,000$ $\$ 69,999)(n=2)$, and upper middle class $(\$ 70,000$ or higher $)(n=3)$. Parental background characteristics included two-parent (a mixture of biological parents and stepparent arrangements) $(n=6)$ and single parent households $(n=2)$. Two of the eight participants were first generation college attendees

\section{Data Collection}

After Institutional Review Board (IRB) approval was granted at both institutions, the first author contacted the Student Athlete Support Services (SASS) Director at each institution and provided a description of the study. Following these initial correspondences, five participants from the HWI and three from the HBCU were identified by the SASS Directors and contacted subsequently by the first author via e-mail. Participants were contacted initially through a forwarded e-mail from the first author to the SASS Directors with a description of the study, a consent form, and interview protocol. Following this e-mail, the first author coordinated a convenient day, time, and location with the SASS Directors and eligible participants to conduct the initial focus group interview. The single focus groups at each institution occurred in an academic building on campus and participants signed two copies of the consent form (one for the first author to retain and one for participants' records). Participants were asked to complete a short demographic questionnaire at the beginning of the focus group. Following the focus group, each participant was solicited for participation in a follow up individual interview. All eight participants agreed and individual interviews were conducted within four weeks after the initial focus group. Similar to the focus group, participants were provided with two consent forms to sign at the beginning of the interview (one retained by the first author and one provided to the participant for their records).

Data collection methods included an 8-item demographic questionnaire (six multiple choice questions and two open-ended questions) (see Table 1), one semistructured focus group (at each institution for a total of two focus groups), and eight semistructured individual interviews. The first author along with a second researcher administered the demographic questionnaire and focus groups whereas the individual interviews were conducted solely by the first author. The first author facilitated questions for both focus groups and individual interviews and a second researcher served as an observer and additional note taker along with the first author during the focus groups. Focus group interview questions (a total of eight structured questions plus additional probing questions) focused on gathering data about participants' motivations for choosing to attend their respective college, the nature of their college experiences (academic, athletic, and social), and key influences that contributed to their positive experiences and academic achievement in college. All questions were centralized on their lived experiences associated with 
their identities as Black female students who participated in competitive athletics. Each focus group lasted between 90 and 120 minutes.

The individual interview protocol (a total of 13 structured questions plus probing questions) focused on acquiring more detailed personal background information, motivations for choosing to attending a D-I institution, and additional reflections on their college experiences particularly key influences that contributed to their positive academic, athletic, and social outcomes. For example, one question related to their motivations for choosing to attend a D-I HWI was "What were your reasons you chose to attend this particular institution?" An example of questions related to their academic experiences are "What challenges did you face academically in college, if any? What factors helped you overcome those challenges?" Similar to the focus groups, questions were centralized on their identities and concurrent lived experiences. Individual interviews ranged from $30 \mathrm{~min}$ to $80 \mathrm{~min}$.

\section{Data Analysis}

The 8-item demographic questionnaire was entered into the Service Product for Statistical Analysis (SPSS) 21.0 software and descriptive statistics were performed (see Table 1). Interview data were analyzed using a blended content analysis and grounded theory coding procedure (Biddle, Markland, Gilbourne, Chatzisarantis, \& Sparkes, 2001; Glaser \& Strauss, 1967; Scanlan, Ravizza, \& Stein, 1989). All codes including themes were in-vivo codes to ensure findings were grounded in participants' voices, perspectives, and experiences (Glaser \& Strauss, 1967; Ryan $\&$ Bernard, 2000). During each phase, in-vivo codes were quantified to facilitate the identification and substantiation of emergent themes (Tashakkori \& Teddlie, 1998). The first phase involved the first author analyzing each transcript, coded them line-by-line, and identified raw data codes. This first phase analysis resulted in 1,150 raw data codes for the HWI focus group, 390 raw data codes for HBCU focus group, 1,248 raw data codes for HWI individual interviews, and 465 raw data codes for the HBCU individual interviews. The larger number of participants at the HWI $(n=5)$ compared with at the HBCU $(n=3)$ resulted in extended discussion and thus more total codes.

The second phase of data analysis involved organizing raw data codes into initial clusters of meaning making themes known as first-level codes. This process resulted in 153 first-level codes for the HWI focus group, 71 first-level codes for the HBCU focus group, 258 first-level codes for HWI individual interviews, and 109 first-level codes for the HBCU individual interviews. The third phase of coding (second-level codes focused on larger clustered themes) resulted in 105 s-level codes for the HWI focus group, 56 s-level codes for the HBCU focus group, 191 s-level codes for the HWI individual interviews, and $86 \mathrm{~s}$-level codes for the HBCU individual interviews. The fourth phase of coding involved constant comparative analyses across datasets to identify general dimensions while acknowledging negative cases. The initial analysis resulted in 28 general dimensions across all qualitative data. At this stage, CCW framework was identified as an applicable theoretical lens to explicate the findings and four final emergent themes were extracted.

Trustworthiness and Subjectivity. Qualitative data quality and trustworthiness was enhanced through data triangulation (heterogeneity among participants' backgrounds), methodological triangulation (one descriptive quantitative and 
two qualitative approaches), member checks (participants' received transcripts and code analyses and provided feedback), multiple investigators/analysts (four trained qualitative researchers), detailed memos (completed by each investigator/ analyst), and the writing of a subjectivity statement (completed by the principal investigator (PI)/first author) (Patton, 2002). The first author is a Black (racial identification) and African American (ethnicity) male researcher and former athlete whose research interests focus on examining the intersection between race, gender, sport, culture, and education. The PI had minimal interaction with participants before the initiation of the study, which resulted in both strengths and limitations ${ }^{6}$. The second author is a Black woman whose research focuses on Black women and their multiple intersecting identities in various collegiate environments. The third author is a Black women whose research focuses on diversity and higher education. Both the second and third author served as analysts and reviewers of coding and data interpretation.

\section{Limitations}

One limitation of the current study was the sample size $(N=8)$, which included three Black female college athletes from a D- I HBCU and five from a D-I HWI. Thus, findings from the study cannot be generalizable to all Black female college athletes across sport participation types, institutional contexts, and academic performance levels. The data collection included two focus groups, eight individual interviews, and a demographic questionnaire and the analysis relied on participants' self-reported perceptions at a single point in time as opposed to including and verifying reports via participant observations, institutional records (i.e., GPAs), information from related sources (e.g., parents, coaches, teammates, advisors, etc.), and/or a longitudinal study. The fact that the lead researcher was male also influenced the interpretation of participants' responses; however, the inclusion of two Black female researchers trained in qualitative research and well-versed in research on Black females in college along with member checks served as strategies to minimize single reviewer bias. The purpose, research questions, and theoretical framework of this study focused on influences related to participants' academic achievement and positive educational experiences and did not examine in-depth barriers or challenges they faced.

\section{Findings}

The primary research questions focused on uncovering key influences that contributed to Black female college athletes' academic achievement and positive college experiences. From the data analysis four themes were identified (see Figure 1). Related to research question one, two personal themes emerged (personal influences). The first theme of "The most important thing to my parents was education" emphasized the extent to which family support and socialization equipped participants with the capital necessary navigate their postsecondary environments. The second theme of "You have to know why you're here" highlighted how participants acquired a student and achievement centric mentality toward their purpose at their respective institutions while also possessing strong athletic identities. Two additional themes emerged related to research question two (institutional influences). 
The third theme of "We have a good rapport with our professors" highlighted the process by which participants developed positive relationships with their professors and benefits derived therein. The fourth theme of "You literally have everything you need to do well" revealed the privileges and subsequent positive outcomes associated with having access to resources on campus by virtue of their athletic status. CCW framework concepts are embedded throughout the presentation of the aforementioned themes.

\section{"The Most Important Thing to My Parents Was Education"}

Family Expectations and Support. Consistent with previous literature (Carter, 2008; Carter-Francique \& Hart, 2010; Carter-Francique, Hart, \& Cheeks, 2015; Cooper \& Cooper, 2015), familial support was among the most salient themes in terms of impactful personal influences on participants' achievement outcomes in college. Angela, a sophomore Business Marketing major and swimmer at the HBCU, described how her parents' expectations and involvement influenced her academic motivation and achievement:

My parents are really hard on me about school, especially my Dad. He really doesn't play when it comes to school. He's very strict on me, and he keeps me focused. And I would probably say if it wasn't for him, I probably wouldn't have any motivation honestly.

Regardless of family composition (i.e., single parent vs. two-parent) and socioeconomic status, each participant cited how their family cultural values of educational attainment and achievement were instilled in them at an early age. Moreover, the presence of this familial capital cultivated their aspirational capital to excel academically because of their race, sex, athletic status, and family background as opposed to in spite of these identities. In concert with Yosso's (2005) CCW framework, these Black female college athletes enrolled at their respective institutions with vital capital that enabled them to overcome challenges such as negative societal stereotypes attributed to their intellectual abilities.

Similarly, participants explained how education was always prioritized above sports. Aniya, a first-year Undecided major (later Human Family and Developmental Studies) and volleyball athlete at the HWI described how education was valued in her family:

The most important thing to my parents was education because that's how you get to college. Besides sports, put sports aside, what's going to get you to college is your education. So I've always been taught to make good grades.

A common example shared among multiple participants was the enforcement that participating in sports was not a right, but rather a privilege granted based upon the prerequisite of academic achievement. It was clear participants possessed high academic standards for themselves as a byproduct of their parents' expectations and support. Isabel, a junior English major and track and field athlete at the HWI, echoed this sentiment when reflecting on her childhood:

My mom is a force to be reckoned with, and if she says no, that means no.

So, she kind of always had my best interests at heart even though sometimes 


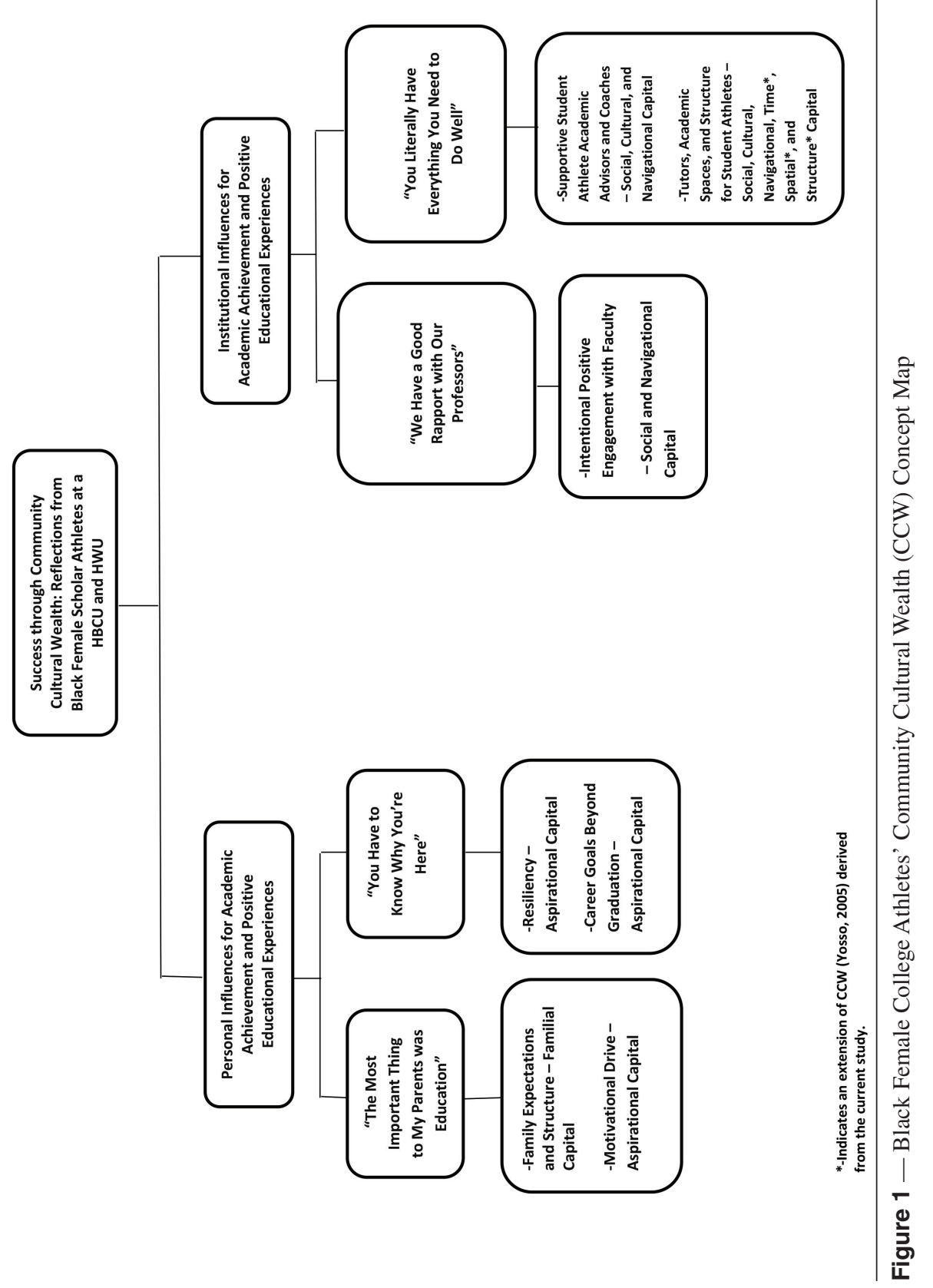


I would be like, "I want to go out." She's like, "You're not going anywhere." So, it kind of made me prioritize. I didn't really need to go out. I needed to stay inside and do something better with myself.

From the participants' comments along with their intersecting identities, it can be surmised that their parents' emphasis on education for their daughters was a form of resistant capital against societal norms that privilege Whiteness and maleness. Thus, the participants' internalized the prioritization of academics as a means to resist negative stereotypes about Black intellectual capabilities and acquire power via education and sport participation as ancillary component of this broader aim. Furthermore, six out of the eight participants (Ashlyn (HWI), Angela (HBCU), Aniya (HWI), Jennifer (HWI), Lucille (HBCU), and Valerie (HWI)) had parents who attended college (social and navigational capital) and each of them referenced how they felt attending college was a family expectation and reiterated through placement in structured enrichment activities (i.e., summer academic programs). Having access to this familial, social, cultural, and navigational capital in the form of their parents being college graduates greatly influenced their perception of academics, the utility value of education, and subsequent academic behaviors/ engagement. Isabel (HWI) and Monique (HBCU), the two participants who were first-generation collegians, also mentioned how college attendance and graduation were instilled in them as family values at an early age and subsequently reinforced throughout their childhood (i.e., scheduled reading time).

Motivational Drive. Beyond the extrinsic presence of familial support, findings also revealed how participants' acquired strong intrinsic motivational mentalities toward academic achievement. Ashlyn, a sophomore Business major and volleyball player at the HWI, offered a poignant narrative about how her family's journey inspired her to pursue educational excellence.

Well, my parents are both educated. They grew up in [a West African country] and they came out here just for a better opportunity. They're both teachers which is not really their trade. Mom was trained in engineering and my Dad was real estate agent. It's just difficult to get into that here [in the U.S.]. So, they became teachers [when they came to the U.S.] and they've been like to school...There's always been this focus for our school. There's always been like do better for yourself, that's really the only way you're ever going to be successful...in terms of your grades...it's really it's you.

Later in her individual interview, Ashlyn explained how her interest in business was motivated by the fact that her family has attempted to start their own business several times, but encountered significant challenges. As a result, she wanted to obtain the information and skills necessary to help her family successfully create and sustain their own business. Her parents' aspirational and resistant capital demonstrated through their own perseverance was transmitted to Ashlyn and inspired her to view education as a means of economic empowerment. Similar stories were conveyed by Monique, a first-year Accounting major and softball player at the HBCU, and Lucille, a junior Liberal Studies Management major and basketball player at the HBCU, about their motivation for pursuing their career interests in an effort to improve their family's plight. Lucille explained how being 
an international college athlete (also from a West African country) and coming from an economically disadvantaged background presented unique challenges, but her mother served as her primary motivation:

I knew my Mom was striving for me to go to school and my Mom was just like I need you to go to school. I want you to be educated. Money's going to come at any time even when you finish school... But like having education is the most important thing.

Whether the participants grew up in a working class, middle class, or upper middle class household, the prioritization of education was instilled in them as a form of resistant capital whereby their acquisition of skills, knowledge, and resources would contribute to the upward mobility of their personal, familial, and cultural plight. Isabel, a first generation collegian at the HWI (junior English major and track and field athlete), described how her aspirational capital was driven to accomplish a feat that no one in her immediate family had attained (a college degree from a U.S. institution):

I would say just wanting something more for myself - something more than what my Mom has or my Dad has or my family has and just being able to... When I get out of school, being able to live how I want and not be restricted by, "Oh, well, I have to do this and I have to do that." I'm safe in myself.

Isabel's sentiment about being "safe in myself" reflected a shared sentiment among these Black female college athletes that education, not sport, was their strongest asset in a society that seeks to marginalize them based on their race and sex. Their early socialization experiences with strong educational values and consistent reinforcement throughout their childhood and adolescence signified the importance of familial and resistant capital, which translated into their personal aspirational capital.

\section{"You Have to Know Why You're Here"}

Resiliency. Another personal influence cited by the participants was their ability to overcome academic obstacles while in college. Although, each of the participants' possessed strong academic and intellectual prowess, they all cited how they experienced varying levels of challenges in the classroom (particularly during their first year of college), but their aspirational capital propelled them to be persistent in their achieving their goals. Ashlyn from the HWI described her transitional challenges during her first year and subsequent resiliency:

When I first got here, freshman, first semester, I was like, 'I am gonna kill it, I am gonna be the best student ever'... Then it started going a little downhill during spring. But now in learning from that, I just went in saying to myself conquering these months is all about taking extra notes and meeting with TAs [teaching assistants].

One of the primary challenges participants faced was balancing their schedules as full-time students and athletes. Unlike, high school where their athletic commitments did not directly interfere with their academic classes, participants had 
to adjust to travel time for away games, longer practices, and other required tasks associated with being a college athlete (e.g., film sessions and study hall hours). Collectively, these transitional challenges had an initial negative impact on their academic performance, but each participant cited how their aspirational capital enabled them to persist and excel. In Ashlyn's case, she activated and transmitted her aspirational capital to overcome academic challenges into vital social and navigational capital by initiating interactions with her TAs. Angela from the HBCU offered a similar story about how she adjusted her approach to academics after having a difficult semester:

Like in the business building, I' $m$ in there all the time. They have...like I said, my least favorite course is accounting, and they do have an accounting tutoring lab here...I'm constantly in there just trying to get help.

In response to academic challenges, participants did not disengage or question their ability to perform, but rather increased their effort and adapted their strategies to ensure positive outcomes. These strategies involved accessing and activating multiple forms of capital including aspirational, social, and navigational via study efforts, effective time management, and engagement with professors, TAs, and academic tutors. In response to challenges she faced in college, Lucille from the HBCU explained how she overcame these challenges:

So it's really difficult unless you're a strong person entirely...You have to know why you're here... But the main goal is like because I love the sport I'm doing and I want education because I'm going to benefit in life, so I don't have to go through other sacrifices. It's going to take me to where I want to get... You just have to stay positive, stay focused, and just believe at the end of the day, all you're going through right now is for a purpose.

A common sentiment shared among the group was the fact that as college athletes they would have to make unique sacrifices different from their nonathlete peers. Participants embraced this challenge and interpreted it as another opportunity to demonstrate their resolve. Lucille's quotes "you have to know why you're here" epitomized the collective possession and activation of aspirational capital described by each participant.

Career Goals Beyond Graduation. The possession of career goals aside from professional sport aspirations was another key influence associated with participants' increased academic effort and performance as well as their overall positive educational experiences. All eight participants possessed clear career goals and were motivated by their early educational experiences and familial influences to attain them, which served as their benchmarks for success. For example, Monique from the HBCU expressed how her desire to become a certified public accountant (CPA) was inspired by her extended family members and her academic selfefficacy in mathematics: "I have a couple family members that are CPAs and I've always been good with numbers. So, in high school I took an accounting class to see if I would like it and I just stuck with it." Each of the participants cited the benefit of having family members who were professionals in various fields and how access to these individuals fueled their personal aspirations both during and 
after college (familial, social, navigational, and aspirational capital). Relatedly, positive identity affirmation associated with education was also nurtured during participants' early educational experiences. Isabel from the HWI described how her early love and passion for reading led to her career interests in becoming an author and college professor:

My personal goals are to have a bunch of books published. I actually have one in the works. I'm like 20,000 words in. I have a 30 page poetry book I want to publish. Professionally, I want to be a professor or teacher or just get paid to write because that's awesome. Like, who doesn't want to do that? Other than that, just I guess keep stepping up like, "Okay, I have this." And, like, what's the next step? Kind of like sports. You always want to better yourself. I kind of want to just keep accumulating whatever I need to accumulate. Like, degrees. If it's like awards, whatever it is.

The possession of clear goals that were not directly related to sport enabled the participants to view their athletic participation within a broader context. This holistic identity intensified their aspirational capital in educational spaces because their plan for their lives extended beyond their athletic roles and performance. All participants possessed aspirational capital that exceeded beyond earning a college degree. Monique (HBCU), Valerie (HWI), Ashlyn (HWI), and Isabel (HWI) expressed their intentions of earning a postbachelor's degree in their fields, Accounting, Medical School, Business Administration, and English, respectively. Although, Aniya (HWI), Jennifer (HWI), Angela (HBCU), and Lucille (HBCU) did not express intentions of pursuing graduate school, each articulated their career goals and the value of earning a bachelor's degree that would best prepare them for postcollege career success (see Table 1).

\section{"We Have Good Rapport With Our Professors"}

Intentional Positive Engagement With Faculty. Another aspect of CCW framework that enhanced participants' academic achievement while in college was their social and navigational capital gained through connections with professors. A common experience among participants was their positive relationship with at least one professor. A major reason cited for these positive relationships was the fact that they took the initiative to meet with their professors outside of class. Ashlyn from the HWI explained her approach to cultivating a positive relationship with her professors: "The one thing that truly makes such a big difference is talking to your professors...I got through so many things because I was always communicating and able to work with him...that's what helped me a lot." Participants described how the athletic culture at their respective schools promoted positive student-faculty interactions. Lucille from the HBCU described how her academic advisors in the athletic department required college athletes to meet with their professors on regular basis and the benefits of these meetings:

With the academics, [athletic] advisors we have right here, they make it mandatory that you have to talk to your professors, talk to them even if they know you are athletes, you still have to go to the office and meet with them and let them know what is going on, email them, talk with them. So I think with that, we have good rapport with professors. 
Instead of relying solely on their academic advisors to communicate to their professors, the participants internalized this communication as primarily their responsibility. Angela from the HBCU described her initiative to meet with professors:

I'm very close to my professors. Like I said in the focus group, my freshman year, I really wasn't very active with them as far as talking to them and talking to them when I needed help. I just thought that I could do it all on my own. But just talking to older students and people that I saw that were successful, they say you should get close with your professor. They have a lot of good connections, and they're willing to help you, and they are. Especially at this school.

Navigational capital in the form of expansive feedback on previous assignments, guidance on how to best prepare for an upcoming exam, tips for completing a paper, and advice on career pursuits were essential to the participants' positive educational outcomes and experiences. Participants were intentional about interacting frequently with individuals outside the athletic department including professors, advisors, and tutors and acquiring useful social and navigational capital, which subsequently enhanced their academic achievement and positive educational experiences.

\section{"You Literally Have Everything You Need to Do Well"}

Supportive College Athlete Academic Advisors and Coaches. As college athletes, the participants benefitted from having access to a range of quality and targeted resources to aide their academic progress (social and navigational capital). Jennifer, a junior Sport Promotions major and basketball player, explained how her athletic academic advisor facilitated her academic achievement:

She holds us more accountable and she makes sure we're doing what we need to do. She makes sure that we're going to class. We have to tell her our grades that we get back, almost as soon as we get them back. She just makes sure that, you know, we're all doing what we're supposed to do because we are student athletes, student comes first. She really lives by that and she makes us realize that.

The additional layers of accountability for their academic performance signaled to them that they were valued as students first and athletes second. Academic advisors provided navigational capital through strategic advising concerning course sequencing to maximize participants' academic performance in major courses. In addition to academic advisors, participants also cited how their respective coaching staffs were engaged and supportive of their academic success. For example, Lucille from the HBCU highlighted how support from her coaches contributed to her academic success:

Yeah, they are really helpful. My team...each coach...they check on you. You meet with them every week, once a week and they check on your academics. Like you tell them where you are in classes, what problem you're facing in classes, if you have any problem. Like they are just really on top of you. If you're going through any problem, they are ready to help you to solve it. So 
we have everything to make sure you are on top of your academics. And yeah, your academic coaches you meet with once a week. You tell them everything about your classes, what's going on, if you have any problem, if there's any progress, if there's a way to come in to talk to the professor...

Aniya from the HWI echoed these sentiments:

So we have meetings with our coaches every other week and you really don't wanna go in there and tell her you failed something. So that just really puts a damper on your day. So you really gotta get good grades cause you have to...she has this notebook and she writes down every single grade you get, for every single class.

Consistent meetings with their coaches who were designated as academic monitors reinforced to participants that their academics were a top priority. The consistent academic support from their advisors and coaches underscored athletic departments' commitment to this subgroup's positive educational experiences.

Tutors, Academic Spaces, and Structure for College Athletes. In addition to supportive athletic staff, the academic resources within the athletic department also facilitated participants' academic achievement. Aniya from the HWI described how she used the tutoring services within the athletic department: "And the academic support here, yeah, [the fact] that you can really get tutors is good, cause I have a tutor for every subject this semester." All eight participants mentioned using tutors at some point in their academic careers through either the athletic department or their respective academic departments. Participants also benefitted from college athlete specific academic support spaces. Ashlyn from the HWI captured consensus among both groups when she said: "We have a great place to study. We have a library...If you need to print something, we have a printer in the [Student Athlete Academic Center]. You literally has everything you need to do well." Although, at times viewed as a contributor to social isolation, these spaces within the athletic department signal to college athletes that their role as student is valued and reflected the institution's commitment to creating conditions that facilitate their success in the classroom. Expanding on CCW framework, the authors described access to spaces that are designed to facilitate positive educational outcomes as spatial capital. College athletes benefit from these support centers similar to how all college students benefit from libraries and additional spaces on campus that are purposefully designed to optimize student intellectual growth and focus on academic development.

Participants highlighted the benefits of having a structured schedule. Valerie, a first-year Pre-Med Biology major and volleyball player at the HWI, described the benefits of athletics on her academic performance:

But I think that athletics kinda has... it has made a structure, it's made it easier, as of now, it's made it easier to do better in academics, cause it makes you sit down and study, it forces you to study...otherwise you're gonna be lazy.

Lucille from the HBCU also expressed the benefits she experienced from a structured athletic schedule: “....any time I have during the day between classes, I'm always in the study hall just to get my classes done...that really helped me." 
Although, none of the participants were required to attend study hall by virtue of their high GPAs, they took advantage of study hall hours to complete their respective assignments. Building on CCW framework, the authors describe college athletes' schedule as structure capital and time capital. Both of the aforementioned forms of capital can yield positive outcomes when implemented in a balanced manner.

\section{Discussion}

The purpose of this study was to explore the experiences of Black female college athletes at a D-I HBCU and HWI and identify key influences that facilitated their academic achievement and positive educational experiences. One of the unique contributions of the current study is the qualitative exploration of Black female college athletes who attended two distinct institutional environments (HBCU and HWI). Previous research has documented Black female college athletes' negative experiences at HWIs (Bernhard, 2014; Bruening et al., 2005; Carter, 2008; Foster, 2003; Harmon, 2009) whereas the current study expands on antideficit research focused on key contributors to this subgroups' positive educational and developmental outcomes in college (Cooper et al., 2016).

The inclusion of Yosso's (2005) CCW framework is another unique contribution of the current study and highlighted various forms of capital possessed and activated by Black female college athletes to foster their academic achievement and positive educational experiences. The five types of capital used by the participants included familial, resistant, aspirational, social, and navigational (Yosso, 2005). In addition, the authors identified extended forms of capital beyond the original CCW framework including spatial, structure, and time. Yosso (2005) conceptualized CCW as resources including knowledge, skills, abilities, and contacts obtained and leveraged by groups that have been historically marginalized in society to navigate contested structural arrangements and social norms. In particular, Black women have adopted a range of productive navigational approaches to experience positive educational outcomes in a society that privileges Whiteness and maleness (Collins, 1986, 1990, 2000; Crenshaw, 1991; hooks, n.d.). The current study fills a gap in the literature by highlighting perspectives from Black female college athletes at a HBCU and HWI who leveraged their CCW to experience positive educational outcomes.

\section{Theoretical Implications}

Among the most prominent findings was the significant influence of familial capital throughout the participants' lifespan (Carter, 2008; Carter \& Hart, 2010; Carter-Francique, Hart, \& Cheeks, 2015; Cooper et al., 2016; Martin, Harrison, \& Bukstein, 2010). Carter and Hart (2010) highlighted that family was among the most important sources of support in comparison with coaches, advisors, counselors, and other individuals connected Black female college athletes. A cornerstone of cultures across the African Diaspora is the reliance on collective familial support particularly in a society where Whiteness is privileged and Black lives, experiences, and outcomes are perpetually oppressed (Collins, 1986, 1990, 2000; Crenshaw, 1991; Yosso, 2005). The familial capital emphasis on education within the current study (and related aspirational capital) also reflected a form of resistant capital whereby these Black families were challenging pervasive stereotypes that deem 
them as intellectually deficient (Yosso, 2005). In concert with CRT, participants offered meaningful counter-narratives that challenge insidious stereotypes and echo findings from previous research on high-achieving Black college athletes that highlights the nurturing of academic achievement through strategic parental involvement (Cooper et al., 2016; Martin et al., 2010).

Moreover, the current study also highlighted how CCW does not operate in isolation, but rather different forms of capital are interconnected and influence each other in meaningful ways. For example, participants' familial capital in the form of high academic expectations and consistent support preceded and served as the foundation for the activation of their aspirational and navigational capital. In Carter, Dortch, and Carter-Phiri's (2017) study, the authors found Black female college athletes who participated in a culturally relevant program at a D-I HWI viewed money, social class, and education as vital forms of power. In a related vein, participants in the current study viewed educational attainment and academic achievement as a means by which they could enhance power over their lives via social class mobility and/or sustainability.

Positive engagement with faculty was also identified in the current study and reflects a consistent theme across the literature on Black female college athletes. This type of engagement falls within the social and navigational capital concepts of the CCW framework (Yosso, 2005). Participants in the current study reflected a similar attitude observed among Black male college athletes in Martin et al.'s (2010) study whereby their positive relationships with faculty were a result of their "eagerness and zeal to learn new concepts, explore different philosophies, and challenge themselves academically" (p. 286). Given the fact that Black college athletes are often stigmatized based on their race, sex, and athletic status, the intentionality by which participants engaged with their professors to communicate their seriousness about academics and the professors subsequent reciprocation of respect and support is a notable finding (Cooper et al., 2016; Martin et al., 2010). Therefore, it could be surmised Black female college athletes' academic self-efficacy, productive academic behaviors, and positive interactions with faculty may serve as a buffer for the negative campus racial climate cited in previous literature particularly at HWIs (Hoffman et al., 2016; Rankin et al., 2011).

Interestingly, consistent with previous HBCU college athlete research (Cooper, 2013; Cooper \& Cooper, 2015), the three HBCU participants highlighted how they received informational, instrumental, emotional, and appraisal support from their professors, which corresponds with the founding missions and organizational cultures of these institutions (Allen et al., 2007; Cooper, 2013; Fleming, 1984). These various types of supports connect with navigational, social, familial, and aspirational capital of the CCW framework (Yosso, 2005). Whereas the five participants at the HWI echo Carter-Francique, Hart, and Cheeks' (2015) findings whereby they primarily received informational and instrumental support from faculty. Notwithstanding, these collective findings underscore the impact of faculty perceptions of and subsequent interactions with Black college athletes. Contrasting these findings to previous comparative studies (Sellers et al., 1997), this study reiterates the notion that the nature and quality of college athletes' experiences in college is contingent upon various factors including their intersecting identities, backgrounds, lived experiences, personalities, and arguably most importantly stakeholders' responsiveness (or lack thereof in many instances) to these characteristics. 
At the institutional level, participants greatly benefitted from the organizational cultures within their respective athletic departments and teams. Participants highlighted how their athletic academic advisors, coaches, tutors, and college athlete specific academic support spaces contributed to their effective time management skills and task-oriented behaviors. Expanding on CCW framework (Yosso, 2005), the authors of the current study describe participants' access to these resources as spatial capital, structure capital, and time capital. Since the NCAA mandated academic counseling and tutoring services for college athletes, the establishment of athletic academic support centers has become commonplace particularly at the D-I level. Despite notable challenges with these spaces at times contributing to social isolation (Comeaux \& Harrison, 2011), findings from the current study indicate they also provide spatial capital for Black female college athletes. Spatial capital involved academic-centric spaces within the athletic department where tutors and resources were available, which improved participants' time on task, focus, and performance. In addition, participants described the benefits of having access to structure capital and time capital, which contributed to their enhanced time management skills and academic performance. Thus, findings illustrate a broader conception of how CCW can be activated and leveraged across time and space by various subgroups.

\section{Implications for Policy and Practice}

One recommendation from the current study for institutions of higher education including athletic departments and higher education professionals is the adoption of CCW framework (Yosso, 2005) as a blueprint for identifying, targeting, and optimizing culturally relevant support for college athletes from diverse backgrounds. Formal structures should be implemented to enhance the transmission and acquisition of multiple forms of capital. One form of support that proved to be pivotal in the lives of these Black female college athletes was their family; therefore, institutions would do well to encourage active involvement of parents and family members. Institutions must find ways to incorporate the engagement and involvement with/ of parents as crucial partners for the continued development and success of their student athletes while in college. Athletic departments and sport teams should prioritize familial involvement in a variety of ways during events such as family weekends as well as throughout the year. In addition, athletic departments and higher education professionals should be intentional about implementing personal and career development activities that allow college athletes to document, discuss, and analyze how familial capital influences their lives and contributes to the development of additional forms of capital.

Another recommendation for institutions of higher education is to create and/ or strengthen more detailed sequential supports for college athlete career development (Cooper, 2016; Navarro, 2015). All eight participants described how their career goals beyond graduation enhanced their focus on and prioritization of their academic engagement and performance. Working in concert with Career Development Offices on campus, athletic departments and higher education professionals can create on-going programs that facilitate college athlete career development from the moment they step on campus through graduation. The authors also propose measuring and nurturing affective and environmental factors such as motivations, 
attitudes, and campus racial climate. Carter-Francique, Hart, and Steward (2013) articulated the need for athletic departments to extend their metrics of academic success beyond graduation rates and GPA to incorporate noncognitive measures (e.g., personal development, skill application to life and career mobility, and networking) when assessing organizational effectiveness. Thus, athletic departments and higher education professionals should engage in comprehensive and ongoing evaluative assessments of their college athletes to identify the nature and quality of their relationships, engagement, and satisfaction (Comeaux, 2015; Comeaux \& Harrison, 2011; Cooper \& Dougherty, 2015) and create action plans for redressing areas of need for specific subgroups.

First, the authors recommend increasing the frequency of positive interactions between faculty and college athletes. Comeaux and Harrison (2007) documented the importance of faculty-student athlete interactions and suggested intentional engagement opportunities should be organized by athletic and academic departments. Thus, formalizing consistent support (i.e., prioritizing time for college athletes to meet with professors and engaged in study groups beyond mandatory study hours) for their academic engagement is recommended (see Bimper, 2015, 2016; Cooper, 2013, 2016) for examples of institutions where this practice has been established). This idea is particularly important for implementation during the first and second academic year as these times have been identified as challenging transitional periods for college athletes. Secondly, coaches' contracts should also be restructured to incentivize the promotion of engagement in educationally purposeful activities among college athletes as opposed to primarily being rewarded for athletic performance and traditional cognitive outcomes such as GSR and academic progress rates (APR) (Cooper, 2016). Thirdly, in particular, additional support could involve is the establishment, strengthening, and/or promotion of Black female centered support programs (Carter-Francique, 2013; Carter-Francique, Dortch, \& Carter-Phiri, 2017).

\section{Conclusion}

Similar to previous antideficit research with Black female college athletes (Cooper et al., 2016), the current study serves as an example of how this subgroup defy negative stereotypes and leverage CCW to experience positive educational and developmental outcomes. Carter-Francique, Dortch, and Carter-Phiri (2017) utilizing Black Feminist Thought (BFT) (Collins, 1986, 2000) emphasized the importance of centralizing Black female college athletes' perspectives and experiences in empowerment driven research:

More specifically, self-definition entails challenging the stereotypes and controlling images that have historically defined Black women by replacing negative stereotypes and controlling images with positive authentic images (Collins, 1986, hooks, n.d.) (p. 36).

Findings from the current study highlight how Black female college athletes used their CCW to navigate a society and educational spaces that privilege Whiteness and patriarchy (Bruening, 2005; Carter, 2008; Collins, 1986, 1990, 2000; Corbett \& Johnson, 2000; Crenshaw, 1991; Porter \& Dean, 2015). The current antideficit study revealed how success through community cultural wealth is 
attained for Black female college athletes when interconnected forms of capital are accessible and strategically activated. This study in conjunction with academic performance data on Black female college athletes emphasizes the need for additional research on and recognition of the unique challenges facing this subgroup, but more importantly ways in which institutions can remove barriers and multiply effective supports for their academic achievement, postcollege career success, and holistic identity development. Future research should continue to employ antideficit perspectives utilizing a range of culturally relevant frameworks such as CRT, CCW, and BFT and centralize the experiences of Black female college athletes.

\section{Notes}

1. The term "college athlete" and "student athlete" will be used interchangeably to refer to students enrolled at NCAA member institutions who participate in intercollegiate athletics. The interchangeable usage will be based on the source referenced.

2. For the purposes of this study, the term female is used to refer to biological sex designation. However, the terms "woman" and "gender" will be used when referenced from sources.

3. The terms "historically White institution (HWI)" will be used to refer to postsecondary institutions that historically excluded the enrollment of non-White students and enroll a majority of White students (Cooper, Cooper, \& Baker, 2016). The authors assert the term HWI, in place of predominantly White institution (PWI), is more accurate to highlight the connection between the origins of these institutions and their current enrollment trends, campus climates, and curricula in contrast to HBCUs.

4. The Black female college athletes in the current study participated in athletics and excelled academically via earning cumulative grade point averages (GPAs) of 2.8 or higher as well as recognized by their respective student athlete academic support staff (SASS) as exemplar academic performing student athletes.

5. The terms "Black" and "African American" will be used interchangeably based on the cited source. Both terms refer to individuals who are socially labeled and self-identify as either "Black" and/or "African American" as it pertains to their racial classification.

6. A strength is the minimal influence of relationship bias or social desirability that can stem from preestablished relationships with participants. A limitation is the restricted amount of rapport established with the participants before data collection, which possibly limited the depth of responses compared with heightened levels of comfort with a someone who they had a stronger preestablished relationship. Nonetheless, the minimal prestudy interactions along with the researcher's intersecting identities with relation to race, athletic status, and cultural backgrounds and the use of the aforementioned quality in qualitative research strategies described in this section added trustworthiness and credibility throughout the research process.

\section{References}

Allen, W.R., Jewel, J.O., Griffin, K.A., \& Wolf, D.S. (2007). Historically Black colleges and universities: Honoring the past, engaging the present, touching the future. The Journal of Negro Education, 76(3), 263-280.

Bell, D. A. (1992). Faces at the bottom of the well: The permanence of racism. NewYork, NY: Basic Books.

Bernhard, L.M. (2014). Nowhere for me to go: Black female student-athlete experiences on a predominantly White campus. Journal for the Study of Sports and Athletes in Education, 8(2), 67-76. https://doi.org/10.1179/1935739714Z.00000000019 
Biddle, S., Markland, D., Gilbourne, D., Chatzisarantis, N., \& Sparkes, A. (2001). Research methods in sport and exercise psychology: Quantitative and qualitative issues. Journal of Sports Sciences, 19(10), 777-809. PubMed https://doi.org/10.1080/026404101317015438

Bimper, A.Y., Jr. (2015). Mentorship of Black student-athletes at a predominately White American university: Critical race theory perspective on student-athlete development. Sport Education and Society, 2, 1-19.

Bimper, A.Y., Jr. (2016). Capital matters: Social sustaining capital and the development of Black student-athletes. Journal of Intercollegiate Sport, 9(1), 106-128. https://doi. org/10.1123/jis.2015-0001

Bruening, J.E. (2005). Gender and racial analysis of sport: Are all the women White and all the Blacks men? Quest, 57(3), 330-349. https://doi.org/10.1080/00336297.2005.10491861

Bruening, J., Armstrong, K.L., \& Pastore, D.L. (2005). Listening to the voices: The experiences of African American female student athletes. Research Quarterly for Exercise and Sport, 76(1), 82-100. PubMed

Carter, A.R. (2008). Negotiating identities: Examining African American female collegiate athlete experiences in predominantly White institutions (Ph.D. dissertation), University of Georgia, Athens, GA.

Carter, A.R., \& Hart, A. (2010). Perspectives on mentoring: The Black female student-athlete. Sport Management Review, 13(4), 382-394. https://doi.org/10.1016/j.smr.2010.01.003

Carter-Francique, A.R. (2013). Black female collegiate athletes experiences in a culturally relevant leadership program. The National Journal of Urban Education \& Practice, 7 , 87-106.

Carter-Francique, A.R., Dortch, D., \& Carter-Phiri, K. (2017). Black female college athletes' perception of power in sport and society. Journal for the Study of Sports and Athletes in Education, 11(1), 18-45. https://doi.org/10.1080/19357397.2017.1285872

Carter-Francique, A.R., Hart, A., \& Cheeks, G. (2015). Examining the value of social capital and social support for Black student-athletes' academic success. Journal of African American Studies, 19(2), 157-177. https://doi.org/10.1007/s12111-015-9295-z

Carter-Francique, A., Hart, A., \& Steward, A. (2013). Black college athletes' perceptions of academic success and the role of social support. Journal of Intercollegiate Sport, 6, 231-246.

Carter-Francique, A.R., \& Richardson, M. (2015). Black female athlete experiences at historically Black colleges and universities. In B. Hawkins, J. Cooper, A. Carter-Francique, \& J.K. Cavil (Eds.), The Athletic Experience at Historically Black Colleges and Universities: Past, Present, and Persistence (pp. 61-84). Lanham, MD: Rowan \& Littlefield.

Charlton, R. (2011). The role of policy, rituals, and language in shaping an academically focused culture in HBCU athletics. Journal of Issues in Intercollegiate Athletics, 4, $120-148$.

Collins, P.H. (1986). Learning from the outsider within: The sociological significance of Black feminist thought. Social Problems, 33(6), S14-S32. https://doi.org/10.2307/800672

Collins, P.H. (1990). Black feminist thought: Knowledge, consciousness, and the politics of empowerment. New York, NY: Routledge.

Collins, P.H. (2000). Black feminist thought: Knowledge, consciousness, and the politics of empowerment (2nd ed.). New York, NY: Routledge.

Comeaux, E. (2015). Organizational learning in athletic departments: Towards an anti-deficit and data-driven approach to academic support for division I athletes. In E. Comeaux (Ed.), Making the connection: Data-informed practices in academic support centers for college athletes (pp. 1-16). Charlotte: Information Age Publishing.

Comeaux, E., \& Harrison, C.K. (2007). Faculty and male student athletes: Racial differences in the environmental predictors of academic achievement. Race, Ethnicity and Education, 10(2), 199-214. https://doi.org/10.1080/13613320701330726

Comeaux, E., \& Harrison, C. K. (2011). A conceptual model of academic success for studentathletes. Educational Researcher, 40(5), 235-245. 
Comeaux, E., Speer, L., Taustine, M., \& Harrison, C.K. (2011). Purposeful engagement of first-year Division I student-athletes. Journal of the First-Year Experience \& Students in Transition, 23(1), 35-52.

Cooper, J.N. (2013). A culture of collective uplift: The influence of a historically Black university/college on Black male student athletes' experiences. Journal of Issues in Intercollegiate Athletics, 6, 306-331.

Cooper, J.N. (2016). Excellence beyond athletics: Best practices for enhancing Black student athletes' educational experiences and outcomes. Equity \& Excellence in Education, 49(3), 267-283. https://doi.org/10.1080/10665684.2016.1194097

Cooper, J.N., Cavil, J.K., \& Cheeks, G. (2014). The state of intercollegiate athletics at historically Black colleges and universities (HBCUs): Past, present, \& persistence. Journal of Issues in Intercollegiate Athletics, 7, 307-332.

Cooper, J.N., \& Cooper, J.E. (2015). Success in the shadows: (Counter) narratives of achievement from Black scholar athletes at a historically Black college/university (HBCU). Journal for the Study of Sports and Athletes in Education, 9(3), 145-171. https://doi. org/10.1080/19357397.2015.1123000

Cooper, J.N., Cooper, J.E., \& Baker, A.R. (2016). An anti-deficit perspective on Black female scholar-athletes' achievement experiences at a historically White institution. Journal for the Study of Sports and Athletes in Education, 10(2), 109-131. https://doi.org/10. 1080/19357397.2016.1218647

Cooper, J.N., \& Dougherty, S. (2015). Does race still matter? A post-BCS era examination of student athletes' experiences at a Division I historically Black college/university (HBCU) and predominantly White institution (PWI). Journal of Issues in Intercollegiate Athletics, 8, 74-101.

Corbett, D., \& Johnson, W. (2000). The African American female in collegiate sport: Sexism and racism. In D. Brooks \& R. Althouse (Eds.), Racism in college athletics: The African American athlete's experience (pp. 199-225). Morgantown, WV: Fitness Information Technology.

Crenshaw, K. (1991). Mapping the margins: Intersectionality, identity politics, and violence against women of color. Stanford Law Review, 43(6), 1241-1299. https://doi. org/10.2307/1229039

Crenshaw, K., Gotanda, N., Peller, G., \& Thomas, K. (1995). Critical race theory: The key writings that formed the movement. New York, NY: The New Press.

Delgado, R., \& Stefanic, J. (2001). Critical race theory: An introduction. New York: New York University Press.

Fleming, J. (1984). Blacks in college. San Francisco: Jossey-Bass Publishers.

Flowers, C.L. (2015). Legal issues and the Black female athletes' collegiate experience at HBCUs. In B. Hawkins, J. Cooper, A. Carter-Francique, \& J.K. Cavil (Eds.), The Athletic Experience at Historically Black Colleges and Universities: Past, Present, and Persistence (pp. 129-144). Lanham, MD: Rowan \& Littlefield.

Foster, K.M. (2003). Panopticonics: The control and surveillance of Black female athletes in a collegiate athletic program. Anthropology \& Education Quarterly, 34(3), 300-323. https://doi.org/10.1525/aeq.2003.34.3.300

Gayles, J. G., \& Hu, S. (2009). Athletes as students: Ensuring positive cognitive and affective outcomes. New Directions for Higher Education, 148, 101-107.

Glaser, B.G., \& Strauss, A.L. (1967). Discovery of grounded theory: Strategies for qualitative research. Chicago, IL: Aldine.

Harmon, N.S. (2009). A study of the experiences of Black college female student athletes at a predominantly White institution. (Ph.D. Dissertation), The University of Iowa, Iowa City, IA.

Hawkins, B., Cooper, J.N., Carter-Francique, A.R., \& Cavil, J.K. (Eds.). (2015). The athletic experience at historically Black colleges and universities (HBCUs): Past, present, \& persistence. Lanham: Rowan \& Littlefield Press. 
Hoffman, J.L., Rankin, S.R., \& Loya, K.I. (2016). Climate as a mediating influence on the perceived academic success of women student-athletes. Journal for the Study of Sports and Athletes in Education, 10(3), 164-184 hooks, b. (n.d.). Understanding patriarchy. Louisville, KY: No Borders. https://doi.org/10.1080/19357397.20 16.1256047

Howard-Hamilton, M. (2003). Theoretical frameworks for African American women. New Directions for Student Services, 104, 19-27. Ladson-Billings, G., \& Tate, W. (1995). Toward a critical race theory of education. Teachers College Record, 97(1), 47-68.

Ladson-Billings, G., \& Tate, W. (1995). Toward a critical race theory of education. Teachers College Record, 97(1), 47-68.

Martin, B., Harrison, C., \& Bukstein, S. (2010). "It takes a village" for African American male scholar-athletes. Journal for the Study of Sports and Athletes in Education, 4(3), 277-295. https://doi.org/10.1179/ssa.2010.4.3.277

Navarro, K.M. (2015). Preparation for life after sport: Data-informed practices for college-athlete career development programs. In E. Comeaux (Ed.), Making the connection: Data-informed practices in academic support centers for college athletes (pp. 91-108). Charlotte: Information Age.

NCAA. (2016). Trends in graduation success rates and federal graduation rates at NCAA Division I institutions. NCAA website. Retrieved from http://www.ncaa.org/sites/ default/files/2016RES_GSRandFedTrends-Final_sc_20161114.pdf

NCAA. (2017). NCAA GSR database. Retrieved from https://web1.ncaa.org/GSRSearch/ exec/homePage

Patton, M.Q. (2002). Qualitative research and evaluation methods (3rd ed.). Thousand Oaks, CA: Sage Publications.

Person, D.R., Benson-Quaziena, M., \& Rogers, A.M. (2001). Female student athletes and student athletes of color. New Directions for Student Services, 93(93), 55-64. https://doi.org/10.1002/ss.5

Porter, C.J. (2013). Identity development in Black undergraduate women: A grounded theory study (Unpublished doctoral dissertation). University of Georgia: Athens, GA.

Porter, C.J., \& Dean, L.A. (2015). Making meaning: Identity development of Black undergraduate women. NASPA. Journal About Women in Higher Education, 2(8), 125-139. https://doi.org/10.1080/19407882.2015.1057164

Porter, C.J. (2017). Articulation of identity in Black undergraduate women: Influences, interactions, and intersections. In L.D. Patton \& N.N. Croom (Eds.), Critical Perspectives on Black Women and College Success (pp. 88-100). New York: Routledge.

Rankin, S., Merson, D., Sorgen, C.H., McHale, I., Loya, K., \& Oseguera, L. (2011). Student-Athlete Climate Study (SACS) Final Report. University Park, PA: The Pennsylvania State University.

Ryan, G.W., \& Bernard, H.R. (2000). Data management and analysis methods. In N.K. Denzin \& Y.S. Lincoln (Eds.), Handbook of qualitative research (2nd ed., pp. 769-802). Thousand Oaks, CA: Sage.

Scanlan, T.K., Ravizza, K., \& Stein, G. (1989). An in-depth study of former elite figure skaters: Sources of enjoyment. Journal of Sport \& Exercise Psychology, 11(1), 65-82. https://doi.org/10.1123/jsep.11.1.65

Sellers, R.M., Kuperminc, G.P., \& Damas, A., Jr. (1997). The college experiences of African American women athletes. American Journal of Community Psychology, 25(5), 699-720. PubMed https://doi.org/10.1023/A:1024691002055

Tashakkori, A., \& Teddlie, C. (1998). Mixed methodology: Combining qualitative and quantitative approaches. Thousand Oaks, CA: Sage.

Tryce, S.A., \& Brooks, S.N. (2010). "Ain't I a Woman?": Black women and Title IX. Journal for the Study of Sports and Athletes in Education, 4(3), 243-256. https://doi.org/ 10.1179/ssa.2010.4.3.243 
Umbach, P. D., Palmer, M. M., Kuh, G. D., \& Hannah, S. J. (2006). Intercollegiate athletes and effective educational practices: Winning combination or losing effort? Research in Higher Education, 47(6), 709-733.

U.S. News \& World Report (2017). Best colleges rankings. Retrieved from https://www. usnews.com/info/blogs/press-room/articles/2016-09-13/us-news-releases-2017-bestcolleges-rankings

Withycombe, J.L. (2011). Intersecting selves: African American female athletes' experiences of sport. Sociology of Sport, 28(4), 478-493. https://doi.org/10.1123/ssj.28.4.478

Yosso, T.J. (2005). Whose culture has capital? A critical race theory discussion of community cultural wealth. Race, Ethnicity and Education, 8(1), 69-91. https://doi. org/10.1080/1361332052000341006 